\title{
PUSH-PULL FARMING SYSTEM CONTROLS FALL ARMYWORM: LESSONS FROM AFRICA
}

\author{
Zeyaur R. Khan ${ }^{\mathrm{a}}$, Jimmy O. Pittchar ${ }^{\mathrm{a}}$, Charles A. O. Midega ${ }^{\mathrm{a}}$ and John A. Pickett ${ }^{\mathrm{b}}$; ${ }^{\mathrm{a}}$ International Centre of Insect \\ Physiology and Ecology (icipe), Nairobi, Kenya; 'School of Chemistry, University of Cardiff, UK; *Corresponding \\ author; zkhan@icipe.org
}

Keywords: Fall armyworm, Spodoptera frugiperda, maize, control, push-pull, Africa

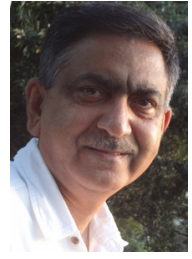

Zeyaur Khan

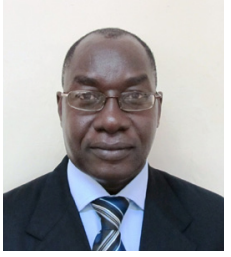

Jimmy Pittchar

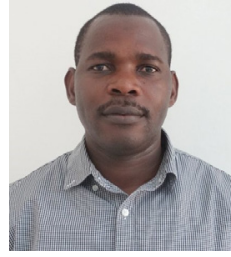

Charles Midega

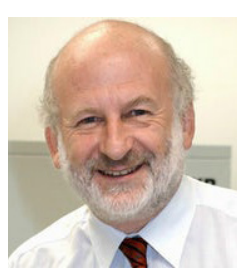

John Pickett

\begin{abstract}
Fall armyworm (FAW) Spodoptera frugiperda invaded Africa, with the first detections being reported in Central and Western Africa in early 2016, and now affects at least 40 countries in Africa, causing up to total crop loss amounting to over $\$ 6.2$ billion p.a. FAW is an invasive polyphagous pest that causes damage to economically important crops and has recently been reported in the Indian sub-continent. Effective control of FAW through use of synthetic chemical pesticides and genetically modified crops such as Bt maize faces challenges including improper use, unaffordability by smallholder farmers and development of resistance by the pest. Additionally, dispersal of FAW larvae into the lower maize plant canopy keeps them out of reach of topical insecticide applications. Integrated pest management (IPM) packages like the push-pull technology which eliminate pesticide use, and deploy natural processes are more suitable and cost-effective. Push-pull is a farming system intensification approach that involves attracting insect pests with trap plants (pull) such as Napier grass (Pennisetum purpureum) or Brachiaria grass, while driving them away from the main crop using a repellent intercrop (push), Desmodium spp., commonly known as desmodium, and attracting natural parasitoids and predators to the field. In the rhizosphere, chemicals secreted by desmodium roots inhibit attachment of germinated striga to maize or sorghum roots and abort germination of striga seeds which are rapidly depleted in the soil. Moreover, it improves soil fertility by fixing nitrogen, improving carbon sequestration, organic matter, moisture retention, and soil biota, and prevents further degradation of soil. The climate-adapted push-pull technology significantly reduces plant damage by FAW and is the first IPM management tool for the pest in Africa, and is well suited to agro-ecosystem intensification needs of smallholder mixed farming systems in Africa and beyond.
\end{abstract}

\section{Introduction}

Fall armyworm (FAW) (Spodoptera frugiperda) (Lepidoptera: Noctuidae) (Figure 1), a pest native to tropical and sub-tropical America, currently affects at least 40 countries in Africa, and is extending rapidly to other countries (Goergen et al. 2016; Cock et al. 2017). An economically important pest, it causes maize (Zea mays) yield losses amounting to $45 \%-67 \%$ of the annual averaged production of maize in the affected countries, among other cereals (Day et al. 2017), costing over $\$ 6.2$ billion p.a. FAW adds to the diversity of Lepidopteran pests of cereal crops and increased negative impacts on agricultural production and food security in Africa. The invasive pest has recently been reported in the Indian sub-continent (Shylesha et al. 2018). FAW directly affects capital costs through increased labour needed and the type of knowledge required to deal with the pest, yield losses and higher financial costs of its control.

\section{Fall armyworm behaviour, biology and ecology}

FAW is a polyphagous pest with a host range that includes more than 80 plant species including maize, sorghum Sorghum bicolor and cotton Gossypium hirsutum. FAW reproduces rapidly, ovipositing egg masses in batches of 100-200 eggs (Day et al. 2017) that hatch into two to four days. Adult moths can survive two to three weeks during which female moths mate multiple

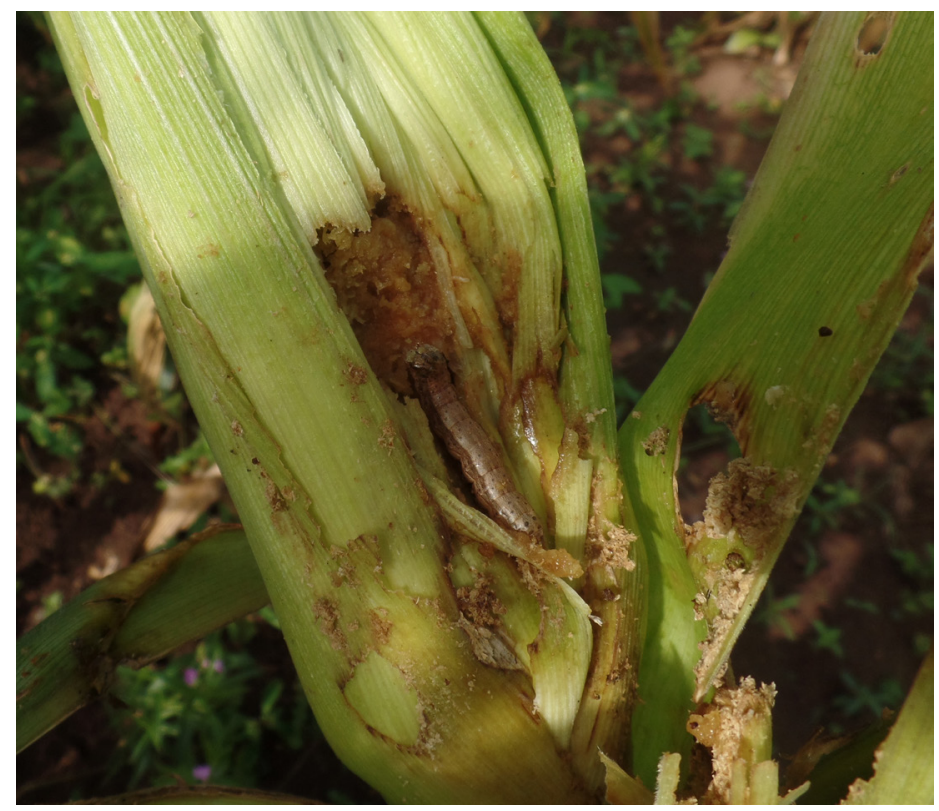

Figure I. FAW larvae in whorl of corn plant. 
times, producing up to 1000 eggs each. The larval stages have 6 instars that voraciously feed on maize leaves at the vegetative growth stage of the plants. At the reproductive stage of maize, the larvae also feed on plant young whorls, ears and tassels and maize ears (Midega et al. 2018). On maize, young larvae eat leaves at night, leaving a 'window pane' effect, and hide in the plant funnel during the day. Larval feeding often kills the growing point and cause 'dead heart'. The larger caterpillars also act as cutworms by entirely sectioning the stem base of maize plantlets. As larvae grow older they hide inside the funnel, limiting the effect of pesticide applications and natural enemies. FAW is a sporadic and long-distance migratory pest whose adult moths are able to fly over $100 \mathrm{~km}$ in a single night (Goergen et al. 2016), having significant economic impacts, up to $100 \%$ crop loss (Day et al. 2017) and finding most farming communities ill prepared to manage the invasion.

\section{Control methods}

Single control methods are costly, unsustainable or ineffective. Several control methods have been tried, including application of pesticides (chemical control), use of microbial organisms that attack FAW in its native range, for example Beauvaria bassiana and Spodoptera frugiperda multiple nucleopolyhedrovirus (SfMNPV), use of predatory insects and parasitic wasps (parasitoids), use of genetically modified crops containing Bt genes that produce proteins that are toxic to the larvae of FAW, mass trapping of male moths using pheromones, preventing them from mating, and integrated pest management (IPM) (Day et al. 2017). Although chemical insecticides have been shown to provide control of the pest (Young, 1979), cases of resistance to some key insecticides (Al-Sarar et al. 2006) and transgenic crops such as Bt maize (Frizzas et al. 2014) have been reported. Overall, synthetic chemical pesticides in Africa have had dismal results as their use depends on farmers' access, knowledge on correct use, consistency of use, purchasing power and the choice of pesticide products (Midega et al. 2012). Moreover, dispersion of FAW larvae lower into the maize plant canopy keeps them out of reach of typical insecticide applications (Cook et al. 2004). Furthermore, pesticides are not affordable for most smallholder famers in Africa. IPM packages that minimize pesticide application and use natural enemies are more suitable and cost-effective for farmers in Africa (Day et al. 2017; Midega et al. 2018). Moreover, agricultural systems in the Americas are different from those in Africa and therefore control methods that have been effective in FAW native habitats may not be effective in Africa. Therefore, an integrated pest management technology like push-pull (www.push-pull. net) that exploits natural processes, including the use of natural enemies, is most promising.

\section{What is push-pull?}

Push-pull www.push-pull.net is a novel cropping system developed by icipe (www.icipe.org) and partners for integrated insect pest, weed and soil fertility management in cereal-livestock farming systems. It is a farming system intensification that improves productivity through exploitation of chemical ecology, agro-biodiversity, plant-plant and insect-plant interactions, and ecological processes through companion cropping. The polycropping innovation holistically provides integrated management of insect pests (stemborers, including Chilo partellus and Busseola fusca, and FAW), parasitic striga weeds, and soil fertility while making efficient use of natural resources to increase farm productivity (Cook et al. 2007).

It involves attracting insect pests with trap plants (pull) whilst driving them away from the main crop using a repellent intercrop (push). Chemicals released by the intercrop roots also cause abortive germination of the parasitic striga weed, providing effective control of the noxious weed. Cereal crops are intercropped with legumes in the genus Desmodium, and planting forage grasses (Napier grass Pennisetum purpureum or Brachiaria cv MulatoII) around this intercrop. The conventional push-pull uses Napier grass as the border crop with silverleaf desmodium (Desmodium uncinatum) as the intercrop. The climate-adapted push-pull, however, uses drought tolerant companion plants, Brachiaria cv MulatoII and Greenleaf desmodium (Desmodium intortum). This technology exploits the fact that adult female insect pests rely on chemical stimuli ('smell') emitted by plants to select those to utilize for egg laying. The desmodium intercrop emits cues that are repugnant to ovipositing female moths thus acting as a 'push', while a grass such as Napier grass emits attractive cues that 'pull' the moths towards itself. These companion plants thus release behaviour-modifying plant chemicals to manipulate the distribution and abundance of stemborers, FAW and beneficial insects for management of the pests (Figure 2).

While this strategy keeps the moths away from the cereal crops, it attracts beneficial organisms that attack the pests' eggs, larvae and pupae. These include parasitoids such as Cotesia sesamiae, a wasp that parasitizes the damaging stages of the pest (larvae), and the generalist predators that are abundant in the push-pull plots (Khan et al. 2014).

The companion plants provide high value animal fodder, increasing milk production and diversifying farmers' incomes. Push-pull also improves soil fertility by fixing nitrogen, improving carbon sequestration, organic matter, moisture retention, and soil biota, and prevents further degradation of soil. Push-pull is economical as it is based on locally available plants, not expensive external inputs, and fits well with traditional mixed cropping systems in Africa. It has been adopted by over 176,000 smallholder farmers in eastern Africa where maize yields have increased from about $1 \mathrm{t} / \mathrm{ha}$ to over $3.5 \mathrm{t} /$ ha., achieved with minimal inputs. Economically, the technology achieves higher factor productivity and returns on farmers' investments (Menale et al. 2018), which makes it both an affordable and sustainable IPM option for Africa.

\section{Climate-adapted push-pull effectively controls fall armyworm}

The climate-adapted push-pull technology effectively controls cereal stemborers and the invasive FAW. Although we fully understand the mechanism involving control of cereal stemborers (Khan et al. 2010), we are still investigating the mechanism (s) by which push-pull controls FAW.

Multi-locational field surveys conducted by icipe staff evaluated functionality of climate-adapted push-pull in 


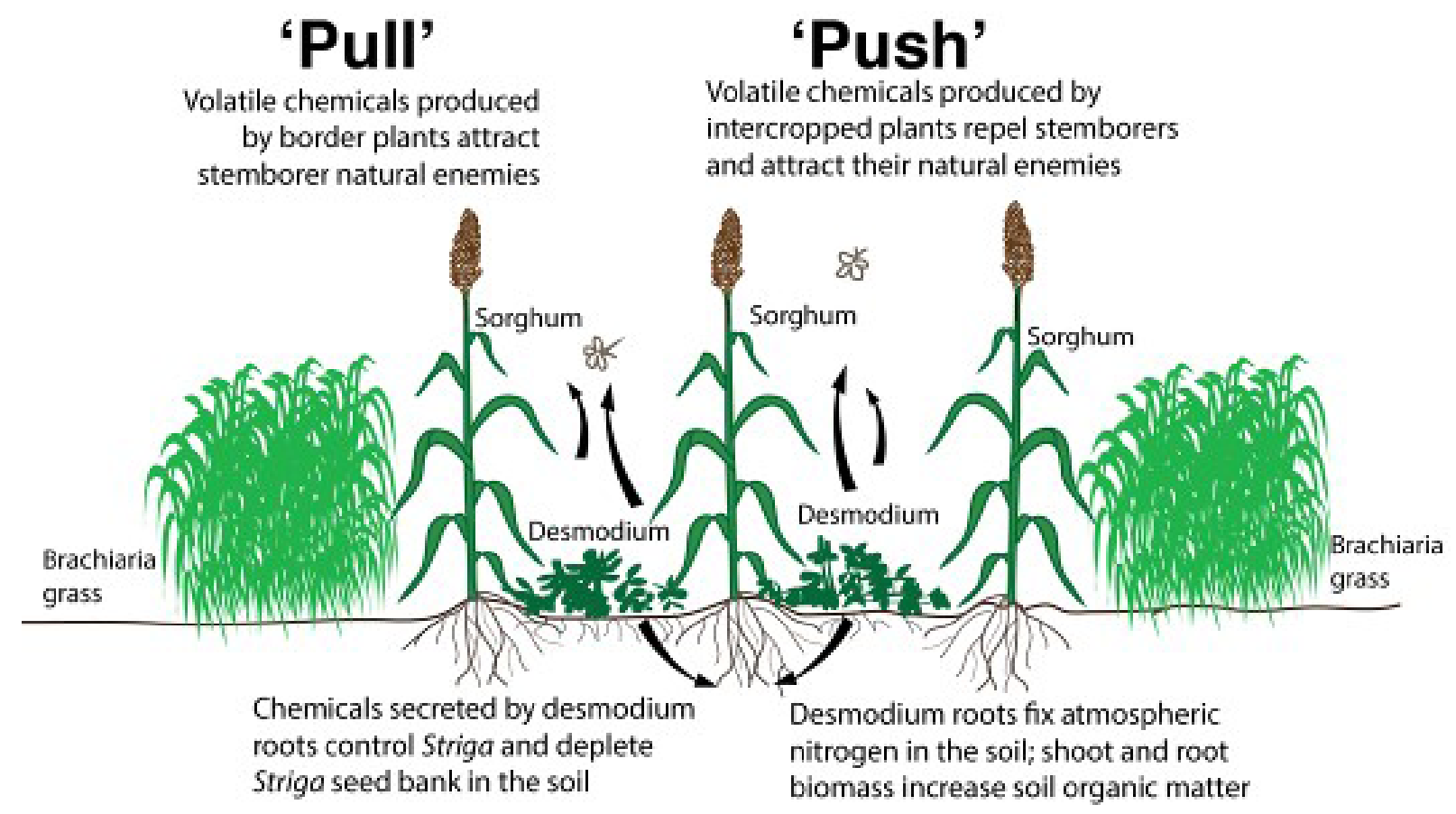

Figure 2. Push-pull technology:A stimulo-deterrent tactic uses aerial volatile organic compounds to mediate oviposition behaviour of gravid stemborers. In the rhizosphere, chemicals secreted by desmodium roots inhibit attachment of germinated striga to maize or sorghum roots and abort germination of striga seeds which are rapidly depleted in the soil.

management of FAW through direct field observations and farmers' perceptions in Kenya, Uganda and Tanzania. Data were collected during the long rainy season (March-August) of 2017 on the number of FAW larvae on maize, percentage of maize plants damaged by the larvae, and maize grain yields. Similarly, farmers' perceptions of the impact of the technology on the pest were assessed. There were highly significant reductions in infestation by FAW larvae and plant damage in climate-adapted push-pull compared to maize monocrop plots: reductions of $82.7 \%$ in average number of larvae per plant and $86.7 \%$ in plant damage per plot were observed in climate-adapted push-pull compared to maize monocrop plots (See Figure 3). Similarly, maize grain yields were significantly higher, approximately 2.7 times, in the climate-adapted push-pull plots. Farmers rated the technology as effective in reducing FAW infestation and plant damage rates. Additional studies have confirmed superiority of push-pull technology in control of FAW relative to other mixed cropping strategies (Hailu et al. In Press). These results demonstrate that the technology is effective in controlling fall armyworm, and represent a technology that can be immediately deployed for management of the pest in East Africa and beyond.

\section{Farmers' testimonies}

Mrs. Lilian Wan'gombe of Kiminini sub-County in Trans Nzoia County of western Kenya has been a push-pull farmer since 1997. Her family has benefited greatly from the technology, enabling her and her family to rear dairy cattle successfully. But in their testimony, the greatest benefit from the technology was its surprising ability to keep the FAW away from their maize crop (Figure 4), while all other surrounding fields were being devastated by the pest.

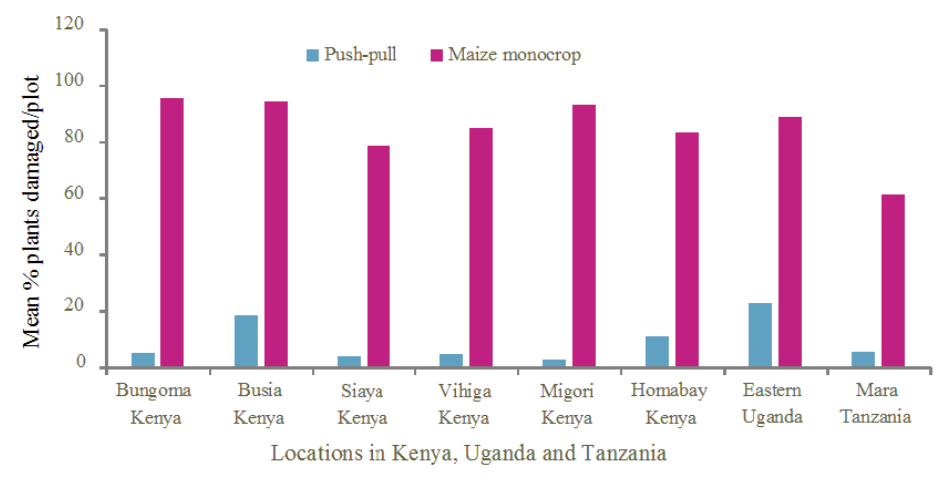

Figure 3. Mean \% damaged maize plants in push-pull and monocrop fields (From Midega et al. 2018).

Like several farmers in eastern Africa, Mr. David Okiya of Kiminini Sub-County, Tranz-Nzoia County in western Kenya also observed that his push-pull field (Figure 5) was not attacked by the FAW. In contrast his other field planted without desmodium (Figure 6) which was severely attacked. He said, "the difference is dramatic; I expect to lose more than $70 \%$ of the crop in the affected maize field, while I will realise a full harvest of maize from the push-pull field".

\section{Conclusion}

Both the African and the Asian continents provide favorable climatic conditions for sustained reproduction of the FAW, which is expected to result in severe damage to crops; and being a new pest in both continents, it might have few natural enemies. Conventional control methods have limited effectiveness, as explained above. Therefore, an IPM approach that is compatible with mixed cropping farming systems of 


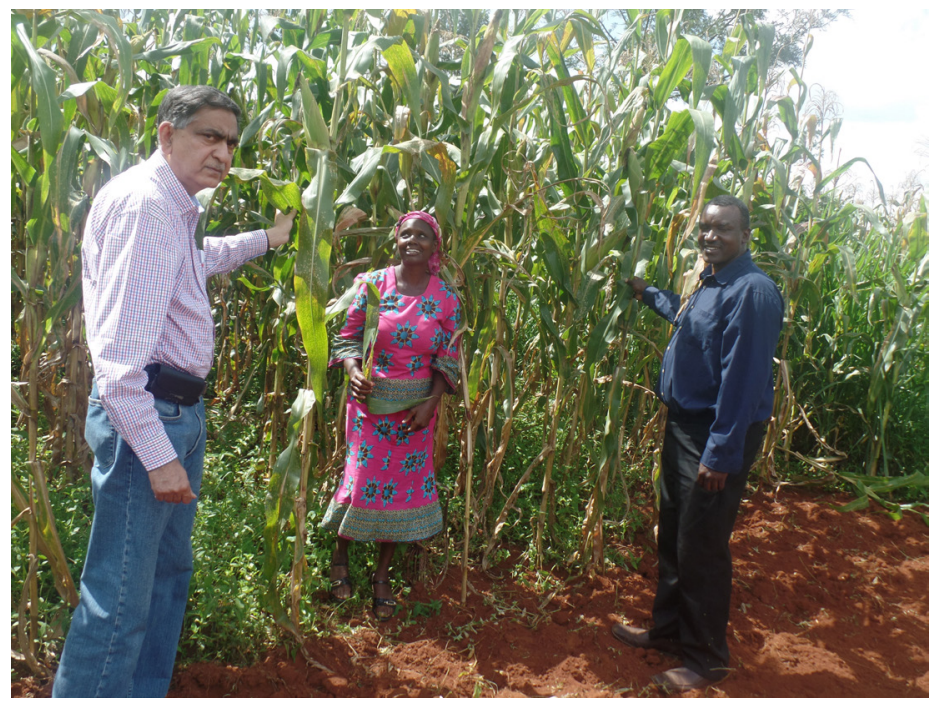

Figure 4. Professor Khan examines a push-pull field of Lilian and John Wan'gombe in Trans Nzoia, western Kenya.

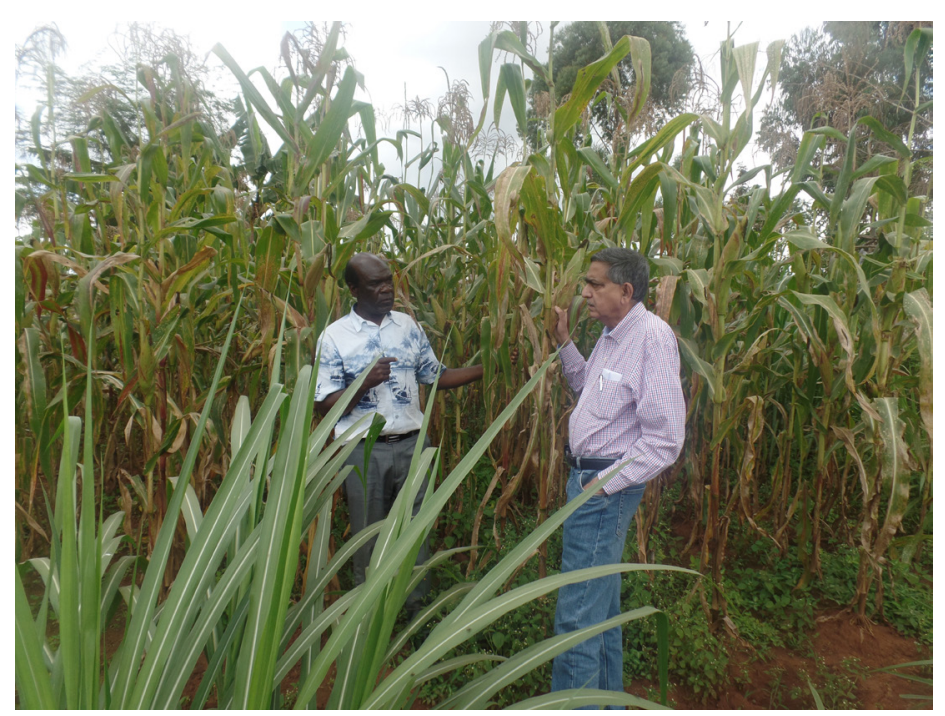

Figure 5. David Okiya's push-pull field unaffected by FAW.

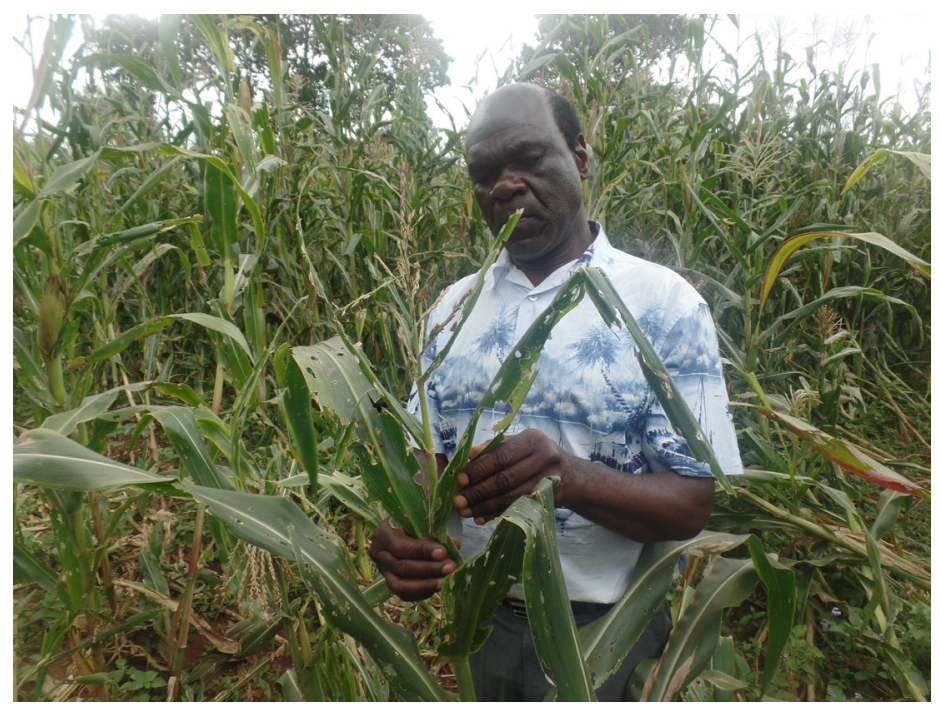

Figure 6. Mr. David Okiya's FAW-damaged maize monocrop field. small and medium scale farmers is necessary. The climateadapted push-pull is the first demonstrated IPM management tool for the FAW in Africa. The technology combines this with other concomitant benefits including control of stemborers and the parasitic striga weeds, improvement of soil health through factors such as nitrogen fixation by desmodium, natural mulching, moisture retention and improvement of soil organic matter and soil biota. The combined benefits, including control of FAW, result in ecologically sustainable higher crop yields, and well suited to agro-ecosystem intensification needs of smallholder mixed farming systems in Africa and beyond.

\section{Acknowledgements}

We gratefully acknowledge the financial support for pushpull research and implementation at icipe by the following organizations and agencies: the European Union, Biovision Foundation, UK's Department for International Development (DFID); Swedish International Development Cooperation Agency; the Swiss Agency for Development and Cooperation (SDC); Norwegian Government and the Kenyan Government. The views expressed herein do not necessarily reflect the official opinion of these donors.

\section{References}

Al-Sarar, A., Hall, F.R. \& Downer, R.A. (2006) Impact of spray application methodology on the development of

resistance to cypermethrin and spinosad by fall armyworm Spodoptera frugiperda (J.E. Smith). Pest Management Science 62, 1023-1031.

Cock, M.J.W., Beseh, P.K., Buddie, A.G., Cafá, G. \& Crozier, J. (2017) Molecular methods to detect Spodoptera

frugiperda in Ghana, and implications for monitoring the spread of invasive species in developing countries. Scientific Reports 7(4103), $10 \mathrm{pp}$.

Cook, S.M., Khan, Z.R. \& Pickett, J.A. (2007) The use of 'pushpull' strategies in integrated pest management.

Annual Review of Entomology 52, 375-400.

Cook, D.R., Leonard, B.R. \& Gore, J. (2004) Field and laboratory performance of novel insecticides against

armyworms (Lepidoptera: Noctuidae). Florida Entomologist 87, 433-439.

Day, R., Abrahams, P., Bateman, M., Beale, T., Clottey, V., et al. (2017) Fall armyworm: impacts and

implications for Africa. Outlooks on Pest Management 28(5), 196-201

Frizzas, M.R., Neto, S.S., de Oliveira, C.M. \& Omoto, C. (2014) Genetically modified corn on fall armyworm and

earwig populations under field conditions. Ciência Rural 44, 203-209.

Goergen, G., Kumar, P.L., Sankung, S.B., Togola, A. \& Tamò, M. (2016) First report of outbreaks of the fall

armyworm Spodoptera frugiperda (J.E. Smith) (Lepidoptera: Noctuidae), a new alien invasive pest in West and Central Africa. PLoS One 11 (10), e0165632.

Hailu, G., Niassy, S., Khan, Z.R., Ochatum, N. \& Subramanian, S. Maize-legume intercropping and push-pull for

management of fall armyworm, stemborers, and striga in Uganda. Agronomy Journal (In press)

Khan, Z.R., Midega, C.A.O., Bruce, T.J.A., Hooper, A.M. \& Pickett, J.A. (2010) Exploiting phytochemicals for developing a 'push- 
pull' crop protection strategy for cereal farmers in Africa. Journal of Experimental Botany 61, 4185-4196.

Khan, Z.R., Midega, C.A.O., Pittchar, J.O., Murage, A.W., Birkett, M.A., Bruce, T.J.A. \& Pickett, J.A. (2014).

Achieving food security for one million sub-Saharan African poor through push-pull innovation by 2020. Philosophical Transactions of the Royal Society B. 369, 20120284.

Midega, C.A.O., Pittchar, J.O., Pickett, J.A., Hailu, G.W. \& Khan, Z.R. (2017) A climate-adapted push-pull system

effectively controls fall armyworm, Spodoptera frugiperda (J E Smith), in maize in East Africa. Crop Protection 105, 10-15.

Midega, C.A.O., Nyang'au, I.M., Pittchar, J., Birkett, M.A., Pickett, J.A., Borges, M. \& Khan, Z.R. (2012) Farmers'

perceptions of cotton pests and their management in western Kenya. Crop Protection 42, 193-201

Kassie, M., Stage, J., Diiro, G., Muriithi, B., Muricho, G., Ledermann, S.T., Pittchar, J.O., Midega, C.A.O., \& Khan,

Z.R. (2018) Push-pull farming system in Kenya: Implications for economic and social welfare. Land Use Policy 77, 186-198.

Shylesha, A.N., Jalali, S.K., Gupta, A., Varshney, R., Venkatesan, T., Shetty, P., Ojha, R., Ganiger, P.C., Navik, O.,

Subaharan, K., Bakthavatsalam, N. \& Ballal, C.R. (2018) Studies on new invasive pest Spodoptera frugiperda (J. E. Smith) (Lepidoptera: Noctuidae) and its natural enemies. Journal of Biological Control, 32(3): 2018, DOI: 10.18311/jbc/2018/21707

Young, R. (1979) Fall armyworm: control with insecticides. Florida Entomologist 62, 130-133.

Yu, S.J. (1992) Detection and biochemical characterization of insecticide resistance in fall armyworm (Lepidoptera: Noctuidae). Journal of Economic Entomology 85, 675-682.

Zeyaur Khan, a Principal Scientist at icipe is lauded for his development and dissemination of the innovative push-pull farming system (www.push-pull.net), which simultaneously addresses issues of crop pests, soil improvement, food security, climate change and sustainability. $\mathrm{He}$ is an Honorary Fellow of the Royal Entomological Society, London, fellow of Entomological Society of America, fellow of African Academy of Sciences, fellow of The World Academy of Sciences (TWAS); recipient of the International IPM Excellence Award (2009), Nan-Yao Su Award for Innovation and Creativity in Entomology (2010), TWAS Prize in Agriculture (20II), and Louis Malassis International Scientific Prize for Outstanding Career in Agriculture (20I5).

Jimmy Pittchar is a Research Scientist at icipe. His research interests interface natural and social sciences, translating bio-sciences into holistic development of agricultural systems, resilient food systems and enabling sustainable impacts of scientific innovations. He conducts inter-disciplinary research on the development, adaptation and adoption of icipe's push-pull technology in Africa, helping smallholder farmers to intensify and sustainably improve their cereal crop and livestock productivity and agro-ecosystem resilience. He holds a BSc degree in mathematics and computer science and a master's degree in social science, specializing in mathematical modelling of human populations, biological and environmental processes driving them, their spatial organization and economic development.

Charles Midega is a Senior Research Scientist at icipe and a Distinguished Africanist Scholar, Cornell University. He holds a PhD in Agricultural Entomology from Kenyatta University, and postdoctoral fellowships from icipe and Kyushu University, Japan. He is actively involved in agricultural development initiatives in Africa, in addition to development and implementation of agricultural technologies, including their adaptation to different agro-ecologies, crop systems and farmer profiles. He is also involved in management of research, including landscape studies, plant signaling and plant-insect interactions. He has authored/co-authored over 100 scientific papers in refereed journals, book chapters, books and educational materials in these fields.

John Pickett is Professor of Biological Chemistry at Cardiff University with particular interests in chemical ecology involving chemically mediated interactions between various organisms including pests attacking plants and animals.

- Chemical characterisation of pheromones and other semiochemicals of plants, and animals including insect pests, extending to beneficial organisms antagonistic to pests

- Stress related chemical signalling by plants and vertebrates including human and farm animals

- Elucidating biosynthetic pathways to pheromones and other semiochemicals together with associated molecular genetics

- Exploiting pheromones and other semiochemicals in management of pests and beneficial organisms by ecology management and genetic modification (GM)

John's contributions to the field of chemical ecology have been acknowledged with the 1995 Rank Prize for Nutrition and Crop Husbandry, election to Fellowship of the Royal Society in 1996, membership of the Deutsche Akademie der Naturforscher Leopoldina in 200I, International Society of Chemical Ecology Medal in 2002, appointment to CBE for services to Biological Chemistry in 2004, and the Wolf Foundation Prize in Agriculture in 2008, among many other honours. He also presented, in 2008, the Royal Society's premier lecture in the biological sciences, The Croonian Prize Lecture, and the Cornell University Lecture in 2009 . He was awarded the International Congress of Entomology Certificate of Distinction, presented at the XXIV International Congress of Entomology in Daegu, Korea. In April 2014, he was elected Foreign Associate of the National Academy of Sciences and, in June 2014, he became President of the Royal Entomological Society.

Similar articles that appeared in Outlooks on Pest Management include - 2014 25(4) 26 I 